\title{
Delta EEG Activity in Left Orbitofrontal Cortex in Rats Related to Food Reward and Craving
}

\author{
FU Yu ${ }^{1,2}$, CHEN Yan-mei ${ }^{1,2}$, ZENG Tao ${ }^{1}$, PENG Yan-ping ${ }^{1}$, TIAN Shao-hua ${ }^{1}$, MA Yuan-ye ${ }^{1,3, *}$ \\ (1. Laboratory of Primate Neuroscience Research and Key Laboratory of Animal Models and Human Disease Mechanisms, \\ Kunming Institute of Zoology, the Chinese Academy of Sciences, Kunming Yunnan 650223, China; \\ 2. Graduate University of the Chinese Academy of Sciences, Beijing 100049, China; \\ 3. Kunming Primate Research Center, the Chinese Academy of Sciences, Kunming Yunnan 650223, China)
}

\begin{abstract}
The orbitofrontal cortex (OFC) is particularly important for the neural representation of reward value. Previous studies indicated that electroencephalogram (EEG) activity in the OFC was involved in drug administration and withdrawal. The present study investigated EEG activity in the OFC in rats during the development of food reward and craving. Two environments were used separately for control and food-related EEG recordings. In the food-related environment rats were first trained to eat chocolate peanuts; then they either had no access to this food, but could see and smell it (craving trials), or had free access to this food (reward trials). The EEG in the left OFC was recorded during these trials. We showed that, in the food-related environment the EEG activity peaking in the delta band (2-4 Hz) was significantly correlated with the stimulus, increasing during food reward and decreasing during food craving when compared with that in the control environment. Our data suggests that EEG activity in the OFC can be altered by food reward; moreover, delta rhythm in this region could be used as an index monitoring changed signal underlying this reward.
\end{abstract}

Key words: Orbitofrontal cortex; EEG; Reward; Craving; Delta band

\section{食物奖赏和渴求行为相关的大鼠左侧眶额叶皮质 Delta 频段脑电活动}

\author{
付 ${ }^{1,2}$, 陈艳梅 ${ }^{1,2}$, 曾 涛 $^{1}$, 彭沿平 ${ }^{1}$, 田绍华 ${ }^{1}$, 马原野 ${ }^{1,3, *}$ \\ (1. 中国科学院昆明动物研究所 灵长类认知实验室, 云南 昆明 650223; 2. 中国科学院研究生院, 北京 100049; \\ 3. 中国科学院昆明灵长类研究中心, 云南 昆明 650223）
}

\begin{abstract}
摘要: 眀额叶皮质与中脑边缘多巴胺奖赏系统有着复杂的相互纤维联系。先前的研究探讨了药物成瘾过程中 眶额叶皮质的脑电活动。在本实验中, 将探讨食物奖赏和渴求过程中该皮质的脑电活动。实验采用了两个环境: 对照环境和食物刺激相关的环境。首先, 训练大鼠在食物刺激相关的环境中吃巧克力花生豆, 而后在该环境中设 置两种不同的刺激方式: 能看到和闻到但不能吃到(渴求实验), 或者仍旧可以吃到巧克力花生豆（奖赏实验）; 同时进行左侧眀额叶皮质的脑电记录。结果发现, 在食物刺激相关的环境中大鼠 Delta 频段 $(2-4 \mathrm{~Hz})$ 的脑电活 动与食物刺激显著相关, 此外, 与在对照环境中相比, 其相对功率在食物渴求时下降而在食物奖赏时升高。本实 验表明, 食物相关的奖励可以改变大鼠眀额叶皮质的脑电活动, 而且, Delta 频段的脑电活动能够作为监测该奖励 的一个指标。
\end{abstract}

关键词: 眶额叶皮质; 脑电图; 奖赏; 渴求; Delta 频段

中图分类号: Q42; Q959.837 文献标识码: A 文章编号: 0254-5853(2008)03-0260-05

The orbitofrontal cortex (OFC) receives efferent projections of the nucleus accumbens (Ray \& Price, 1993;
Koob \& Bloom, 1988) and the ventral tegmental area (Oades \& Halliday, 1987). The mesolimbic dopamine

Received date: 2008-01-17; Accepted date: 2008-02-28

Foundation items: National Science Foundation of China (30470553;30530270;30670669; 30770700); 973 Program (2005CB522803; 2007CB947703); 863 Program (O7013810; 2006AA02A116); The Major State Basic Research of China (2003CB716600); Chinese-Finnish International Collaboration Project-neuro (30621130076); Program of CASC (KSCX1-YW-R-33;YZ200737); National Key Technologies R \& D Program and Yunnan Science and Technique Program (2006PT08-2)

收稿日期：2008-01-17; 接受日期：2008-02-28

* 通讯作者 (Corresponding author), E-mail: yuanma0716@vip.sina.com

第一作者（First author）, E-mail: fyfuyu@tom.com 
(DA) pathway, which projects from the ventral tegmental area to the nucleus accumbens, is important for mediating the perception of reward (Berridge, 1996; Rolls, 2004). Previous studies have suggested that the left OFC rather than the right is associated with a strong reward bias (Pizzagalli et al, 2005).

Electroencephalogram (EEG) is a sensitive measure to study the global activity of the brain. Evidence shows that EEG activity is associated with many important functions, such as learning and memory (Basar et al, 2001; Basar et al, 1999). EEG activity in the OFC is altered during the development of drug dependence and tolerance (Sosina, 1993; Wikler \& Altschul, 1950; Grasing \& Szeto, 1993; De \& Caballero, 1989), such as with morphine (Liu et al, 2005; Sun et al, 2006). However, data related to EEG activity in the OFC during the development of reward and craving of general substances, such as food, is limited.

Previous studies have indicated that eating behavior is mainly motivated by the reward value of the food, which was available in large amounts, rather than by feelings of hunger or maintaining homeostasis (Berridge, 2004). In addition, food craving was driven by the presence of stimuli, which also predicted the rewarding effect of food (Rolls, 1997).

In this study, we recorded EEG activity in the left OFC during the development of food reward and craving to further our understanding of the changes in EEG activity in this region in the process of general substance reward.

\section{Methods}

\subsection{Animals}

Experiments were performed on ten male Sprague-Dawley rats (Animal House Center, Kunming Medical College, PR China) weighing 300-350g. They were housed in individual cages under constant temperature and humidity conditions on a 12-h light/12-h dark cycle. The amount of rodent chow was adapted in order to maintain nearly constant body weight. Water was freely available all the time. All experimental and animal care procedures were carried out in accordance with the guidelines for the National Care and Use of Animals approved by the National Animal Research Authority.

\subsection{Surgery}

As previously described (Sun et al, 2006), surgery was performed under pentobarbital sodium $(40 \mathrm{mg} / \mathrm{kg}$; Shanghai Chemical Factory, PR China) anesthesia. After a midline scalp incision, a burr hole was drilled in the skull over the left OFC. A Teflon-insulated recording electrode was implanted in the left hemisphere OFC according to the following stereotaxic corrdinates: (relative to bregma) anteroposterior (AP), $3.7 \mathrm{~mm}$; mediolateral (ML), 2.4mm; dorsoventral (DV), 4.6mm (Paxinos \& Watson, 1998). Two stainless steel watch screws implanted in the bone above the right cerebral regions served as both reference (AP, 3mm; ML, 2mm) and ground (AP, $-5 \mathrm{~mm}$; ML, $2 \mathrm{~mm}$ ) electrodes. Two or more additional support screws were positioned, and the entire ensemble was secured to the skull with dental acrylic. All electrodes were attached to male pins that were secured in a rectangular three-by-one pin array and secured with dental acrylic. In addition, a general penicillin antibiotic was injected (50000 units per rat; i.m.; Harbin Pharmaceutical Group, PR China) immediately after the surgery. Rats were allowed at least one week to recover from surgery. The locations of the recording electrode were confirmed histologically after the EEG experiment. Data were excluded from any rats in which the recording locations were misplaced.

\subsection{Apparatus for EEG recording}

With the socket on the head of the rat, the electrodes were first connected by a cable to an amplifier (bandpass: $0.5-100 \mathrm{~Hz}$, with no $50 \mathrm{~Hz}$ filter). The cable was suspended to allow the rat free movement. The amplified EEG signals were digitalized with an AD (analog to digital) board (biphase, $1000 \mathrm{~Hz}$ ), and then displayed instantly and saved by a computer.

EEG recording was performed in two chambers (60 $\mathrm{cm} \times 30 \mathrm{~cm} \times 50 \mathrm{~cm}$ ). Chamber A was painted white with a textured floor, which served as the control environment. Chamber B was painted with dark stripes (5 cm width), and the floor was smooth, which served as the stimulus-related environment.

\subsection{Experimental procedure}

The experimental procedure consisted of three phases: habituation, training and testing (Fig. 1). EEG recording was performed during the testing phase.

Habituation: rats were placed into chamber A for 30 min before being removed. After $15 \mathrm{~min}$, they were placed in chamber B for $30 \mathrm{~min}$. This procedural sequence represented a trial, and took place on each of the five habituation days. In this phase no food was offered in both chambers.

Training: following habituation, the same procedure was conducted except that the rats stayed in the chambers for $5 \mathrm{~min}$ only. In addition, rats were given free 
access to chocolate peanuts in chamber $\mathrm{B}$, as well as a perforated bottle containing the same chocolate peanuts. This training phase continued over 6 days, with one trial taking place in the morning and the other in the evening. In all, food was always offered in chamber B but not in chamber A.

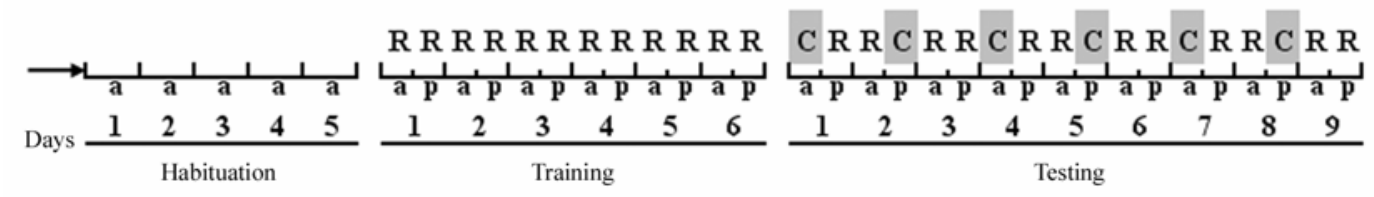

Fig. 1 Schematic illustration of the experimental procedure

The experimental procedure included three phases: habituation, training and testing. "R", the rats were given free access to chocolate peanuts; "C", the rats were presented with only a perforated bottle containing chocolate peanuts allowing no access to food; "a”, the trial was performed in the morning; "p”, the trial was performed in the evening. EEG recording was performed during the testing phase.

Testing: the same procedure was applied in the testing phase, with an exception of including craving trials. One craving trial was followed by two reward trials. This phase comprised 18 trials in total, including 6 craving trials and 12 reward trials. The reward trials were the same as trials in the training phase. The only difference between the reward trials and the craving trials was that in the craving trials, the rats were presented with only a perforated bottle containing chocolate peanuts allowing no access to the food. In summary, there was no food in chamber A, but in chamber B food was offered during reward trials and not offered during craving trials.

\subsection{Data analysis and statistics}

As previously described (Liu et al, 2005), EEG activity was examined by off-line analysis and spectral analysis was performed using Matlab 6.5 software. After computer-assisted rejection of EEG segments with artifacts, the relative power across various frequency bands were characterized for (1) delta: $2-4 \mathrm{~Hz}$, (2) theta: 4-8Hz, (3) alpha: 8-12 Hz, (4) beta: $12-20 \mathrm{~Hz}$ and (5) gamma: $20-100 \mathrm{~Hz}$.

Based on our experimental design, for each rat, the

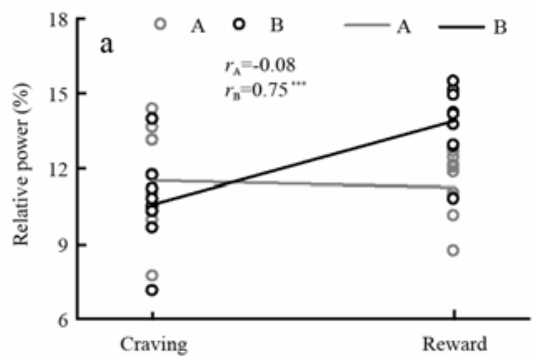

relative EEG power in each frequency band was averaged for 12 reward trials and for 6 craving trials in chamber A and chamber B. Pearson correlations were used to assess the relationship between changes in relative EEG power and food-related stimuli. Differences were assessed with analysis of variance (ANOVA) with repeated measures, using the SPSS 13 statistical software. Stimulus (craving and reward) and chamber (A and B) were two within-group factors. Data were expressed as mean \pm SEM. A level of $P<0.05$ was considered significant.

\section{Results}

As shown in Fig. 2, during the testing phase the two food-related stimuli, craving and reward, were used for animals $(n=9)$ in chamber B. Pearson correlation analysis revealed no correlation between the relative EEG power and the stimulus, in any frequency band, in chamber $\mathrm{A}$ ( $r=-0.08,0.02,0.09,0.2$ and -0.07 for delta, theta, alpha, beta and gamma bands, respectively; $P>0.05$ for all). In contrast, in chamber $\mathrm{B}$, there was a positive correlation between the relative power and the stimulus in the delta

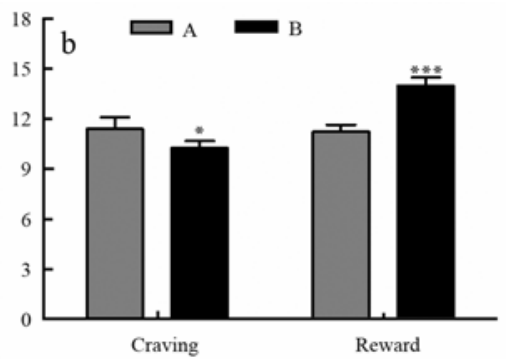

Fig. 2 Food craving and reward during the testing phase induced changes in relative EEG power in the delta frequency band in chamber A and B

a: Pearson correlation analysis showed that the relative power in the delta band showed a significant stimulus-dependent change in chamber B but not in chamber A; b: The mean relative power in the delta band decreased during food craving and increased during food reward in chamber $\mathrm{B}$, compared with that in chamber $\mathrm{A}$. ${ }^{*} P<0.05$; *** $P<0.001$. 
frequency band ( $r=0.75, P<0.001)$, but not in the other frequency bands $(r=-0.25,-0.34,0.28$ and -0.07 for theta, alpha, beta and gamma bands, respectively; $P>0.05$ for all).

ANOVA with repeated measures on the delta frequency band showed a significant main effect of stimulus $\left[F_{(1,8)}=75.98 ; P<0.001\right]$ and chamber $\left[F_{(1 \text {, }}\right.$ $\left.{ }_{8)}=8.29 ; P<0.05\right]$ and interaction effect of stimulus $\times$ chamber $\left[F_{(1,8)}=69.41 ; P<0.001\right]$. Further analysis with a paired Student's $t$-test revealed that the relative power in the delta band decreased during food craving and increased during food reward in chamber $\mathrm{B}$, when compared with that in chamber A.

\section{Discussion}

In this study, the EEG activity in the left OFC was investigated in rats during the development of food reward and craving in a certain environment. In this environment, a significant correlation between the relative EEG power and the food-related stimulus was observed in the delta frequency band only. Moreover, this frequency band showed increased power during food reward and decreased power during food craving when compared with that in the control environment.

Our finding was that the activity in the delta band showed significant correlation with the food-related stimulus in a certain environment, reflected by relative power increased during food reward and decreased during food craving when compared to that in the control environment. Firstly, our data are in accordance with studies on cocaine in humans. For example, a reduction in delta power in the frontal cortex during touching and seeing cocaine cues has been observed, suggestive of craving, while an increase was found during guided imagery of cocaine, indicative of analogical reward (Reid et al, 2003). Cocaine also produced an increase in delta coherence over the prefrontal cortex, indicating the involvement of delta activity in the rewarding properties of cocaine (Reid et al, 2006). In addition, a decrease in delta power during withdrawal in cocaine-preferring polysubstance abusers suggested craving (Roemer et al, 1995). Secondly, during food deprivation, a decrease in delta power has been found in humans (Sulimov, 1995).

Indeed, the delta band has been linked with reward motivation by an evolutionary interpretation based on brain oscillations (Knyazev \& Slobodskaya, 2003). For example, the delta activity increased after administration of testosterone (Schutter \& Van Honk, 2004), which has been related to reward motivation in humans and animals
(Van Honk et al, 2004). On the other hand, the OFC has an important relationship with the mesolimbic DA reward system, mediating the perception of reward (Berridge, 1996; Rolls, 2004). Previous studies have shown that the OFC dysfunction is associated with disturbances in reward motivation (Rolls, 2004). Therefore, in the present study, EEG activity peaking in the delta band in the OFC was probably associated with the reward and craving bias towards food.

In our previous studies, EEG activity in the OFC in monkeys decreased after morphine injection, and this decrease lasted for a longer period in the gamma frequency band (Liu et al, 2005). Moreover, in the OFC in rats, gamma activity showed decreases and increases during the morphine administration and withdrawal period, respectively (Sun et al, 2006). In the present study, EEG activity, especially peaking in the delta band, could be affected by food reward and craving, which is in agreement with our previous studies. On the basis of these findings, we confirm that the OFC plays an important role in the reward motivation either for morphine or for food, which could be monitored by EEG spectrum.

Although the EEG recording was well-controlled by disassociating the effects of body and jaw movements while the subjects were moving or eating, chewing or sniffing artifacts may still have contaminated our EEG signals. However, previous studies and our own data suggest that the effects of these additional factors on the present results should be minor. The rate of chewing pellets in adult male rats varies between 4 and $6 \mathrm{~Hz}$ (Weijs, 1975). This frequency range was again tested, and was found to increase with age in infant rats, and by 18 or 21 days of age, reached the rate of $4-5 \mathrm{~Hz}$ (Westneat \& Hall, 1992). Besides, sniffing and other rhythmic movements are always associated with the theta band of the EEG (Kepecs et al, 2006). Taking all this into account, if these movement artifacts affected our EEG signals, the activity in the theta band would be expected to show some correlation with food stimulus. However, this frequency band revealed no significant alterations in this study.

In addition, we only recorded the left OFC, but several studies have shown the possibility that activity localized in the OFC may represent more generalized EEG activity (Zuo et al, 2007). Therefore, whether our findings in this region could be found in other brain regions, as well as in more global activity, are interesting subjects for future investigation. 
In conclusion, EEG activity in the left OFC in rats seems to be altered by food reward, and delta EEG activity in this region could be an index that monitors changed signals underlying this reward.

\section{References:}

Basar E, Basar-Eroglu C, Karakas S, Schurmann M. 2001. Gamma, alpha, delta, and theta oscillations govern cognitive processes [J]. Int J Psychophysiol, 39(2-3): 241-248.

Basar E, Basar-Eroglu C, Karakas S, Schurmann M. 1999. Are cognitive processes manifested in event-related gamma, alpha, theta and delta oscillations in the EEG? [J]. Neurosci Lett, 259(3): 165-168.

Berridge KC. 1996. Food reward: brain substrates of wanting and liking [J]. Neurosci Biobehav Rev, 20(1): 1-25.

Berridge KC. 2004. Motivation concepts in behavioral neuroscience [J]. Physiol Behav, 81(2): 179-209.

De AI, Caballero A. 1989. Chronic morphine administration in cats: effects on sleep and EEG [J]. Pharmacol Biochem Behav, 32(2): 519-526.

Grasing K, Szeto H. 1993. EEG changes with different levels of morphine self-administration [J]. Neuropharmacology, 32(6): 543-553.

Kepecs A, Uchida N, Mainen ZF. 2006. The sniff as a unit of olfactory processing [J]. Chem Senses, 31(2): 167-179.

Knyazev GG, Slobodskaya HR. 2003. Personality trait of behavioral inhibition is associated with oscillatory systems reciprocal relationships [J]. Int J Psychophysiol, 48(3): 247-261.

Koob GF, Bloom FE. 1988. Cellular and molecular mechanisms of drug dependence [J]. Science, 242(4879): 715-723.

Liu N, Liu Y, Fan Y, Yu H, Wilson FA, Ma Y, Hu X. 2005. EEG activities in the orbitofrontal cortex and dorsolateral prefrontal cortex during the development of morphine dependence, tolerance and withdrawal in rhesus monkeys [J]. Brain Res, 1053(1-2): 137-145.

Oades RD, Halliday GM. 1987. Ventral tegmental (A10) system: neurobiology. 1. Anatomy and connectivity [J]. Brain Res, 434(2): 117-165.

Paxinos G, Watson C. 1998. The rat brain in stereotaxic coordinates [M]. Orlando Florida: Academic Press.

Pizzagalli DA, Sherwood RJ, Henriques JB, Davidson RJ. 2005. Frontal brain asymmetry and reward responsiveness [J]. Psychol Sci, 16(10): 805-813.

Ray JP, Price JL. 1993. The organization of projections from the mediodorsal nucleus of the thalamus to orbital and medial prefrontal cortex in macaque monkeys [J]. J Comp Neurol, 337(1): $1-31$.

Reid MS, Flammino F, Howard B, Nilsen D, Prichep LS. 2006. Topographic imaging of quantitative EEG in response to smoked cocaine self-administration in humans[J].
Acknowledgments: We greatly appreciate Wendy S Adams for her kind help with revising the manuscript in English.

Neuropsychopharmacology, 31(4): 872-884.

Reid MS, Prichep LS, Ciplet D, O'Leary S, Tom M, Howard B, Rotrosen J, John ER. 2003. Quantitative electroencephalographic studies of cue-induced cocaine craving [J]. Clin Electroencephalogr, 34(3): 110-123.

Roemer RA, Cornwell A, Dewart D, Jackson P, Ercegovac DV. 1995. Quantitative electroencephalographic analyses in cocaine-preferring polysubstance abusers during abstinence [J]. Psychiatry Res, 58(3): 247-257.

Rolls ET. 1997. Taste and olfactory processing in the brain and its relation to the control of eating [J]. Crit Rev Neurobiol, 11(4): 263-287.

Rolls ET. 2004. The functions of the orbitofrontal cortex [J]. Brain Cogn, 55(1): 11-29

Schutter DJLG, vVan Honk J. 2004. Decoupling of midfrontal delta-beta oscillations after testosterone administration [J]. Int $J$ Psychophysiol, 53(1): 71-73.

Sosina VD. 1993. The EEG analysis of the interrelationships of structures of the thalamofrontal system during the recovery of conditioned reflex behavior of amygdalectomized rats [J]. Neurosci Behav Physiol, 23(5): 398-403.

Sulimov AV. 1995. EEG spectral analysis in the hunger dominant in man [J]. Zh Vyssh Nerv Deiat Im I P Pavlova, 45(6): 1095-1100.

Sun N, Li Y, Tian S, Lei Y, Zheng J, Yang J, Sui N, Xu L, Pei G, Wilson FA, Ma Y, Lei H, Hu X. 2006. Dynamic changes in orbitofrontal neuronal activity in rats during opiate administration and withdrawal [J]. Neuroscience, 138(1): 77-82.

Van Honk J, Schutter DJLG, Hermans EJ, Putman P, Tuiten A, Koppeschaar H. 2004. Testosterone shifts the balance between sensitivity for punishment and reward in healthy young women [J]. Psychoneuroendocrinology, 29(7): 937-943.

Weijs WA. 1975. Mandibular movements of the albino rat during feeding [J]. J Morphol, 145(1): 107-124.

Westneat MW, Hall WG. 1992. Ontogeny of feeding motor patterns in infant rats: An electromyographic analysis of suckling and chewing [J]. Behav Neurosci, 106(3): 539-554.

Wikler A, Altschul S. 1950. Effects of methadone and morphine of the electroencephalogram of the dog [J]. J Pharmacol Exp Ther, 98(4:1): 437-446.

Zuo YF, Wang JY, Chen JH, Qiao ZM, Han JS, Cui CL, Luo F. 2007. A comparison between spontaneous electroencephalographic activities induced by morphine and morphine-related environment in rats [J]. Brain Res, 1136(1): 88-101. 